\title{
Modeling the Constitutive Relationship of Al-0.62Mg-0.73Si Alloy Based on Artificial Neural Network
}

\author{
Ying Han ${ }^{1, *}$, Shun Yan ${ }^{1}$, Yu Sun ${ }^{2}$ and Hua Chen ${ }^{1}$ \\ 1 Key Laboratory of Advanced Structural Materials, Ministry of Education, Changchun University of \\ Technology, Changchun 130012, China; yanshunccgy@163.com (S.Y.); chenhua@ccut.edu.cn (H.C.) \\ 2 National Key Laboratory for Precision Hot Processing of Metals, Harbin Institute of Technology, \\ Harbin 150001, China; yusun@hit.edu.cn \\ * Correspondence: hanying_118@sina.com; Tel.: +86-431-8571-6396
}

Academic Editors: Myoung-Gyu Lee and Yannis P. Korkolis

Received: 18 February 2017; Accepted: 23 March 2017; Published: 26 March 2017

\begin{abstract}
In this work, the hot deformation behavior of 6A02 aluminum alloy was investigated by isothermal compression tests conducted in the temperature range of $683-783 \mathrm{~K}$ and strain-rate range of $0.001-1 \mathrm{~s}^{-1}$. According to the obtained true stress-true strain curves, the constitutive relationship of the alloy was revealed by establishing the Arrhenius-type constitutive model and back-propagation (BP) neural network model. It is found that the flow characteristic of 6A02 aluminum alloy is closely related to deformation temperature and strain rate, and the true stress decreases with increasing temperatures and decreasing strain rates. The hot deformation activation energy is calculated to be $168.916 \mathrm{~kJ} \mathrm{~mol}^{-1}$. The BP neural network model with one hidden layer and 20 neurons in the hidden layer is developed. The accuracy in prediction of the Arrhenius-type constitutive model and BP neural network model is eveluated by using statistics analysis method. It is demonstrated that the BP neural network model has better performance in predicting the flow stress.
\end{abstract}

Keywords: deformation behavior; constitutive model; BP neural network; aluminum alloy

\section{Introduction}

Deformation behaviors of metal materials are considered as the comprehensive presentation of material properties and processing parameters, such as temperature, strain rate and strain [1-4]. Since the flow behaviors of materials provide valuable information and crucial instructions for thermoplastic processing, an increasing number of researchers have paid great attention to this field. In order to reveal the internal influence of processing parameters on the flow characteristics of materials, some constitutive models have been established [5]. At present, mainly three kinds of constitutive models have been broadly accepted, including analytical models, phenomenal models and empirical models [6-8]. Specifically, analytical models are developed based on the plastic deformation theories of kinetics and dynamics of dislocation. As a result, these models require a thorough understanding of the physical mechanisms controlling deformation behavior of materials. However, it is almost impossible for analytical models to be employed in practical application due to coupled influence of various processing parameters. As for phenomenal models, though less closely related to physical theories, they still depend on explicit understanding of deformation mechanisms. Such models usually consist of several separate equations, each of which is responsible for a fixed processing domain. Therefore, the generality and simplicity of phenomenal models are often limited. Empirical models are aimed at researching the quantitative relationship between true stresses and processing parameters. Regression analysis technique is constantly employed to establish equations and statistical methods are 
performed to evaluate the performance of the model. Therefore, empirical models do not need details about physical or chemical revolution involved during the deformation process. The Arrhenius-type constitutive model is recognized to be one of the most commonly used empirical models and has been successfully applied to various alloys, including magnesium alloys [9], titanium alloys [10,11], aluminum alloys [12] and steels [13]. In contrast, the artificial neural network (ANN) model does not refer to any mathematical model, and it only learns from examples and recognizes patterns from a series of inputs and outputs without any prior assumptions about their nature. Since it is not involved in physical interpretation of plastic deformation mechanisms, the ANN model acts as a robust and intelligent data information treatment system. It has now been recognized as a powerful tool in the field of material science and increasingly applied by a growing number of scholars. For instance, Li et al. [14] compared the ANN model with the Arrhenius-type constitutive model regarding the hot deformation behavior of an Al-Zn-Mg alloy. Ji et al. [15] used a back-propagation neural network model, which was trained with Lavenberg-Marquardt learning algorithm, to study the high-temperature flow behavior of Aermet100 steel. In the research, the performance of the ANN model was evaluated by using a wide variety of standard statistical indices, which turned out that the extrapolation ability of neural network model was very high in the proximity of training domain. Li et al. [16] conducted a comprehensive and comparative study on Zerilli-Armstrong, Arrhenius-type and ANN models in terms of their prediction ability of hot deformation behavior of T24 steel. Quan et al. [17] applied ANN to predict the flow stress of as-cast Ti-6Al-2Zr-1Mo-1V alloy, which suggested that the ANN model has a good capacity to model complicated flow behavior of titanium alloy. Haghdadi et al. [18] utilized ANN to predict the hot deformation behavior of an A356 aluminum alloy, indicating the fact that the trained ANN model was a robust tool to characterize the high-temperature flow behavior of the studied alloy. Despite considerable research work regarding the application of the ANN model in terms of deformation behavior of various materials, the essential differences between the Arrhenius-type constitutive model and the ANN model has not been clearly revealed and application limitation of both methods should be explained.

6A02 aluminum alloy is one of the significant machinable aluminum alloys, which has been extensively used in the fields of aerospace and auto-industry due to its good ductility, high specific strength and satisfied corrosion resistance. In this work, the Arrhenius-type constitutive model and the ANN model are developed and a comprehensive comparison between them is conducted to study the high-temperature flow behavior of 6A02 aluminum alloy.

\section{Materials and Methods}

In the present work, the raw material was 6A02 aluminum alloy. The chemical composition and starting microstructure of the alloy are presented in Table 1 and Figure 1, respectively. It can be seen that the grains of 6A02 aluminum alloy are equiaxed and the average grain size is about $200 \mu \mathrm{m}$.

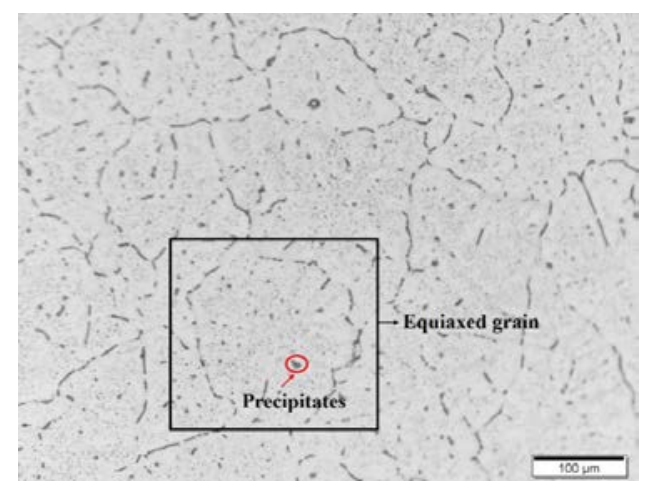

Figure 1. The starting microstructure of the 6A02 aluminum alloy. 
Table 1. The chemical composition of $6 \mathrm{~A} 02$ aluminum alloy.

\begin{tabular}{cccccccccc}
\hline Element & $\mathbf{M g}$ & $\mathbf{S i}$ & $\mathbf{F e}$ & $\mathbf{M n}$ & $\mathbf{C u}$ & $\mathbf{N i}$ & $\mathbf{T i}$ & $\mathbf{Z n}$ & $\mathbf{A l}$ \\
\hline $\mathrm{Wt} \%$ & 0.62 & 0.73 & $<0.05$ & $<0.05$ & $<0.01$ & $<0.01$ & $<0.01$ & $<0.01$ & $\mathrm{Bal}$ \\
\hline
\end{tabular}

The cylindrical compressive specimens were obtained from a bar and subsequently machined into $6 \mathrm{~mm}$ in diameter and $9 \mathrm{~mm}$ in height. Isothermal compression tests were carried out on the Gleeble-1500D simulator (Harbin Institute of Technology, Harbin, China) in the temperature range of $683-783 \mathrm{~K}$ with an interval of $20 \mathrm{~K}$, and the strain rates were selected as $0.001,0.01,0.1$ and $1 \mathrm{~s}^{-1}$. The surfaces of specimens were grinded by sandpaper to remove the oxide layer and guarantee smoothness. Thermocouples were welded in the middle of specimens to measure the temperature during the experimental process. In addition, the graphite powder was applied on both surfaces of specimens to reduce the friction coefficient between the specimen ends and the anvils. The specimens were heated at a rate of $10 \mathrm{~K} / \mathrm{s}$ up to deformation temperature, and held for $3 \mathrm{~min}$ to maintain a uniform temperature in the sample and reduce the material anisotropy. The testing specimens were subject to be compressed to a total true strain of approximately 0.6. The stress and strain variations were automatically recorded by a computer equipped with a data acquisition system. As the compression was completed, the deformed specimen was immediately quenched in water to preserve the hot deformation microstructure. The procedure of compression tests is shown in Figure 2.
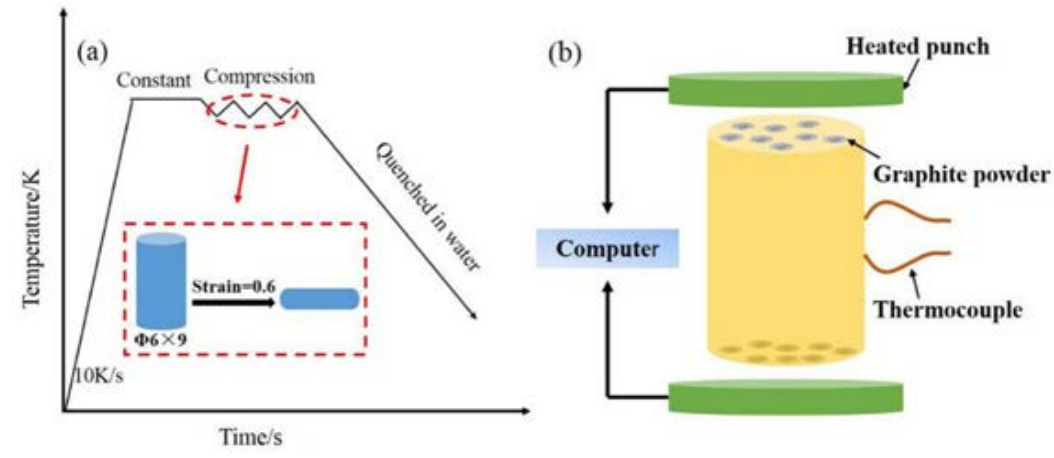

Figure 2. Schematic illustration of experimental procedure (a) and experimental device (b).

\section{Results and Discussion}

\subsection{Flow Behavior}

The true stress-true strain curves obtained from isothermal compression tests at the strain rate of $0.01 \mathrm{~s}^{-1}$ and the temperature of $723 \mathrm{~K}$ are shown in Figure 3. It can be observed from this figure that the flow stress is strongly dependent on the strain rate and deformation temperature. At the strain hardening stage, dislocation multiplication plays a dominant role, the true stress increases rapidly with increasing strain up to a peak value in this stage. While at the dynamic softening stage, the true stress drops gradually due to dynamic recrystallization. Finally, the equilibrium between strain hardening and dynamic softening occurs and the true stress remains at a stable state. It is also noted from Figure $3 \mathrm{~b}$ that the flow stress at low strain rates of 0.001 and $0.01 \mathrm{~s}^{-1}$ are more likely to become stable, which illustrates that the completed dynamic recrystallization has been occurred. Generally, the relationship between true stress and processing parameters of the studied alloy are highly nonlinear. Moreover, similar deformation characteristics of the other alloys are also observed by many researchers [19-21]. 


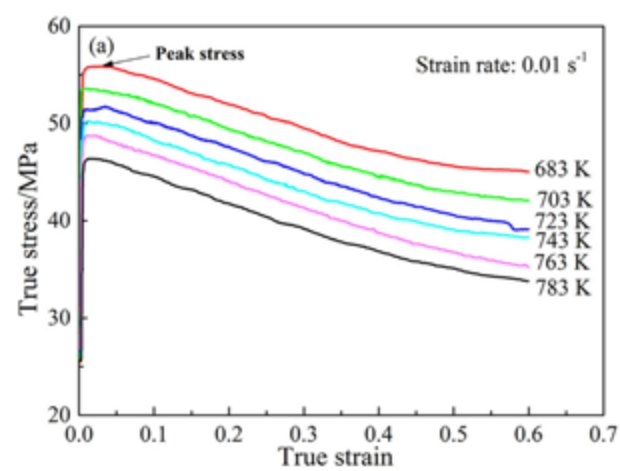

(a)

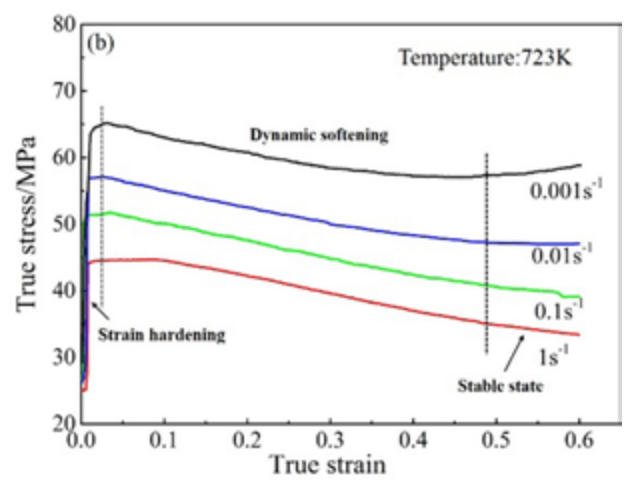

(b)

Figure 3. Typical true stress-true strain curves of $6 \mathrm{~A} 02$ alloy at (a) $\dot{\varepsilon}=0.01 \mathrm{~s}^{-1}$ and (b) $T=723 \mathrm{~K}$.

\subsection{Arrhenius-Type Constitutive Model}

During the hot deformation process of metals and alloys, the correlation between flow stress, strain rate and temperature can be presented by using the Arrhenius-type constitutive model presented as follows:

$$
\dot{\varepsilon}=A[\sinh (\alpha \sigma)]^{n} \exp (-Q / R T)
$$

where $A, \alpha$ and $n$ are the material constants, $\dot{\varepsilon}$ is the strain rate $\left(\mathrm{s}^{-1}\right), \sigma$ represents the flow stress (MPa), $Q$ refers to the activation energy for hot deformation $\left(\mathrm{J} \mathrm{mol}^{-1}\right), T$ is the absolute temperature in Kelvin, and $R$ is the gas constant $\left(8.314 \mathrm{~J} \mathrm{~mol}^{-1} \mathrm{~K}^{-1}\right)$. According to the Taylor series deployment method, the Arrhenius constitutive equation can be interpreted as:

$$
\begin{gathered}
\dot{\varepsilon}=A_{1} \sigma^{n 1} \exp [-Q / R T](\alpha \sigma<1.2) \\
\dot{\varepsilon}=A_{2} \exp (\beta \sigma) \exp [-Q / R T](\alpha \sigma>1.2) \\
\dot{\varepsilon}=A\left[\sinh (\alpha \sigma)^{n}\right] \exp [-Q / R T](\alpha \sigma \text { taking any value })
\end{gathered}
$$

where $A_{1}=A \alpha^{n}, A_{2}=A / 2^{n}$, and $\alpha=\beta / n_{1}$.

The natural logarithm form of the equations above can be indicated as:

$$
\begin{gathered}
\ln \dot{\varepsilon}=\ln A_{1}-Q / R T+n_{1} \ln \sigma \\
\ln \dot{\varepsilon}=\ln A_{2}-Q / R T+\beta \sigma \\
\ln \dot{\varepsilon}=\ln A-Q / R T+n \ln [\sinh (\alpha \sigma)]
\end{gathered}
$$

The peak values of flow stress are presented in Table 2. With these experimental data fitted into Equations (5) and (6), the values of $n_{1}$ and $\beta$ are derived from mean slope of the curves of $\ln \dot{\varepsilon}-\ln \sigma$ and $\ln \dot{\varepsilon}-\sigma$ in Figure $4 a, b$, and they are found to be 18.396 and 0.349 , respectively. Therefore, $\alpha$ is determined as $\alpha=\beta / n_{1}=0.019$. Besides, the value of $n$ is calculated by:

$$
n=\left[\frac{\partial \ln \dot{\varepsilon}}{\partial \ln (\sinh (\alpha \sigma))}\right]_{T}
$$


Table 2. Peak values of flow stress of 6A02 alloy during hot deformation.

\begin{tabular}{ccccccc}
\hline \multirow{2}{*}{ Strain Rate/s $^{-1}$} & \multicolumn{7}{c}{ Flow Stress/MPa } \\
\cline { 2 - 7 } & $\mathbf{6 8 3 ~ K}$ & $\mathbf{7 0 3 ~ K}$ & $\mathbf{7 2 3} \mathbf{~ K}$ & $\mathbf{7 4 3 ~ K}$ & $\mathbf{7 6 3 \mathbf { K }}$ & $\mathbf{7 8 3} \mathbf{~ K}$ \\
\hline 0.001 & 47.90 & 46.86 & 44.66 & 43.13 & 42.19 & 40.47 \\
0.01 & 55.88 & 53.60 & 51.76 & 50.23 & 48.78 & 46.37 \\
0.1 & 63.62 & 61.86 & 57.12 & 55.48 & 53.59 & 50.67 \\
1 & 76.00 & 68.19 & 65.17 & 63.71 & 60.80 & 59.74 \\
\hline
\end{tabular}

It is found that $n$ turned out to be 13.962 from mean slope of the curves of $\ln \dot{\varepsilon}-\ln [\sinh (\alpha \sigma)]$ shown in Figure 4c. $Q$ can be obtained by taking partial derivative of both sides of Equation (7) to $1 / T$ :

$$
Q=n R\left[\frac{\partial \ln (\sinh (\alpha \sigma))}{\partial(1 / T)}\right]_{T}=R n S
$$

The $S$ value is found to be 1.455 from mean slope of $\ln [\sinh (\alpha \sigma)]-1000 / T$ illustrated in Figure $4 \mathrm{~d}$. As a result, the value of $Q$ can be determined as $168.916 \mathrm{~kJ} \mathrm{~mol}^{-1}$. The $Q$ value of the studied alloy is compared with that of other aluminum alloys calculated following the same procedure used for the present 6A02 alloy [22-26], which is presented in Figure 5. It can be observed that the $Q$ value in this work is much smaller than most of the other kinds of aluminum alloys. In fact, 6A02 aluminum alloy is known to exhibit greater temperature dependence in the reduction of flow stress than other aluminum alloys, which is also proved by this work. While the hot deformation is a thermal activation course, activation energy is recognized as a significant indicator for expression of the energy required to overcome the barriers in the metal forming process at elevated temperatures, and it thereby directly reflects the difficulty degree for the hot deformation. As a result, the low value of $Q$ means that the deformation for this alloy is easy at high temperatures and the dynamic recrystallization easily occurs. In addition, the large difference of $Q$ values is visible in the same series of alloys such as 6A02 and 6A82, which demonstrates that the chemical composition and heat treatment state exert a decisive effect on the $Q$ value of aluminum alloys. Yang et al. [23] suggested that the activation energy of $\mathrm{Cu}$-rich alloys is higher than that of $\mathrm{Cu}$-free alloys. The high $Q$ value of $6 \mathrm{~A} 82$ aluminum alloy may be related to the high $\mathrm{Cu}$ content.
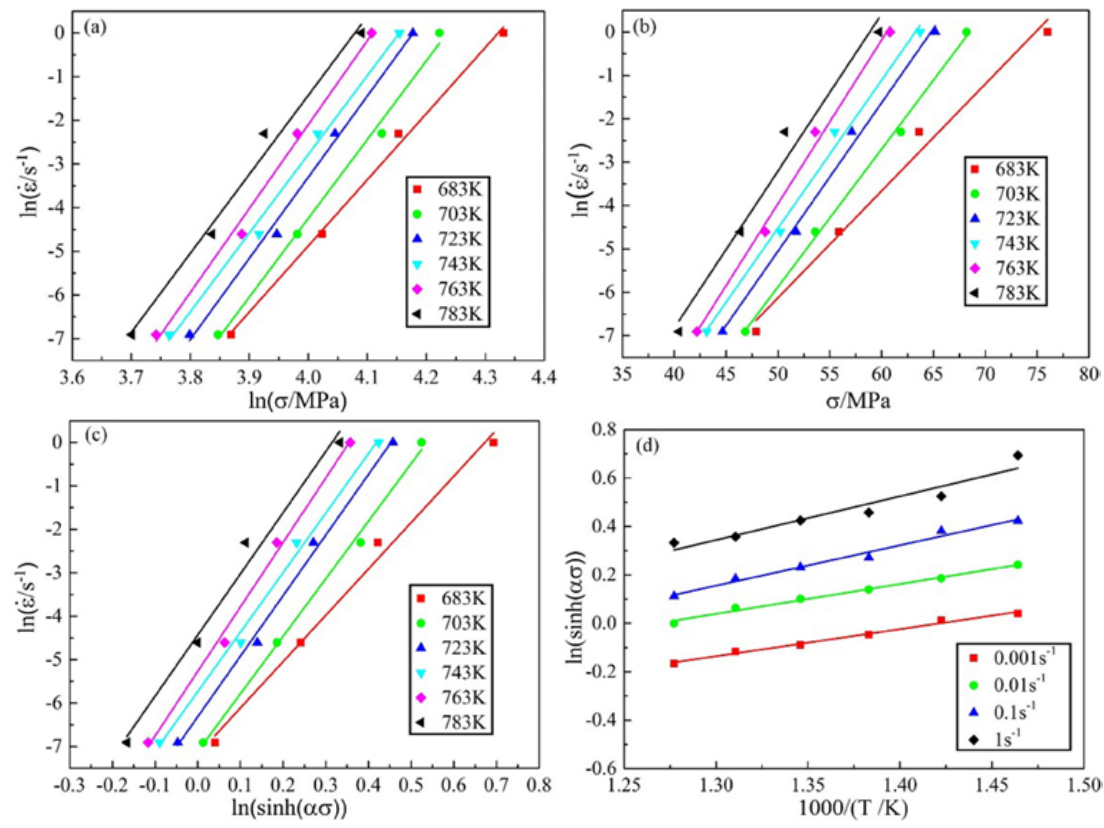

Figure 4. Relationship among stress, strain rate and temperature at a strain of 0.1: (a) $\ln \dot{\varepsilon}-\ln \sigma$; (b) $\ln \dot{\varepsilon}-\sigma ;(\mathbf{c}) \ln \dot{\varepsilon}-\ln [\sinh (\alpha \sigma)]$ and (d) $\ln [\sinh (\alpha \sigma)]-1000 / T$. 


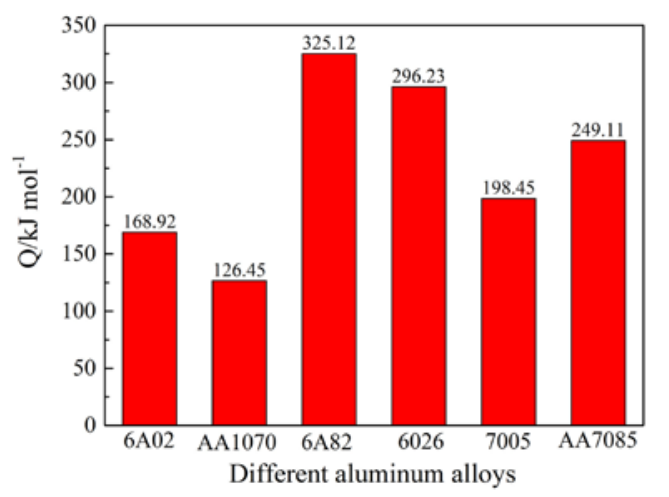

Figure 5. The comparison of $Q$ values among different aluminum alloys.

It is acknowledged that the influence of deformation temperature and strain rate on the flow behavior can be evaluated by the Zener-Hollomon parameter [27], which can be defined as:

$$
Z=\dot{\varepsilon} \exp (Q / R T)
$$

Taking the natural logarithm form of Equation (10) leads to the following equation:

$$
\ln Z=\ln \dot{\varepsilon}+Q / R T
$$

According to Equation (7), Equation (11) can be adapted as:

$$
\ln Z=\ln A+n \ln [\sinh (\alpha \sigma)]
$$

The relationship between $\ln Z$ and $\ln [\sinh (\alpha \sigma)]$ is plotted in Figure 6 with experimental data at peak stress. The intercept corresponding to $\ln A$ is obtained as 21.701. It is noted that the correlation coefficient $(R)$ for the linear regression of $\ln Z-\ln [\sinh (\alpha \sigma)]$ reaches 0.981 , which indicates that the hyperbolic-sine function is in good agreement with experimental results. Therefore, the Arrhenius-type constitutive equation of the studied aluminum alloy at peak stress can be developed as:

$$
\dot{\varepsilon}=e^{21.701}[\sinh (0.019 \sigma)]^{13.962} \exp (-168916 / R T)
$$

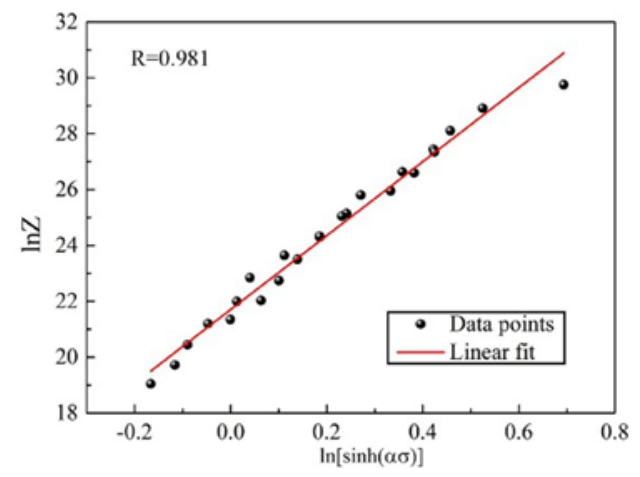

Figure 6. Relationship between flow stress and Zener-Hollomon parameter.

\subsection{Artificial Neural Network Modeling}

Back-propagation (BP) neural network is a forward multi-layer network of one-way transmission [28]. It can be known that a BP neural network is made up of input layer, hidden layer and output layer. 
In the present work, the inputs were comprised of deformation temperature, strain rate and strain, while the true stress was identified as the output variable. Each data processing unit in the layer is called a neuron, whose property is usually controlled by an activation function. Tan-sig, log-sig and purelin are three derivable functions that can be employed as the activation. In order to obtain the best combination by two of them. The performance of different groups with 20 hidden layer neurons was revealed by mean square error (MSE), which is presented in Table 3. It was found that the MSE of the tansig-purelin group is the smallest, which was only 0.113 . Therefore, tansig function is chosen as the input-hidden layer activation function and purelin is determined as the hidden-output layer activation function.

In the BP neural network structure, neurons of the same layer are not coupled with each other. When the input data passes through the network, the output is calculated and subsequently compared with the target. If the deviation exceeds the predetermined threshold, a reverse transmission process will initiate to correct the weight of each neutron. The above actions will not terminate until the deviation can be accepted.

Table 3. Performance of different activation function groups.

\begin{tabular}{ccc}
\hline $\begin{array}{c}\text { Input-Hidden Layer Activation } \\
\text { Function }\end{array}$ & $\begin{array}{c}\text { Hidden-Output Layer Activation } \\
\text { Function }\end{array}$ & $\begin{array}{c}\text { Mean Square Error } \\
\text { (MSE) }\end{array}$ \\
\hline tansig & tansig & 0.222 \\
tansig & purelin & 0.113 \\
tansig & logsig & 0.289 \\
purelin & tansig & 0.139 \\
purelin & purelin & 1.862 \\
purelin & logsig & 0.167 \\
logsig & tansig & 0.732 \\
logsig & purelin & 0.491 \\
logsig & logsig & 1.094 \\
\hline
\end{tabular}

In this work, a feed-forward neural network model trained with BP learning algorithm will be established; 192 data points as the input database was used. Before training the network, both input and output variables have to be normalized within the range from 0 to 1 in order to obtain a valid form for the neural network model to recognize, which can be treated as Equation (14):

$$
X^{*}=\frac{X-0.95 X_{\min }}{1.05 X_{\max }-0.95 X_{\min }}
$$

where $X$ is the original data which refers to temperature, strain and flow stress; $X^{*}$ is the normalized data of the corresponding $X ; X_{\min }$ and $X_{\max }$ are the minimum and maximum values of $X$, respectively. Given that the strain rate changes sharply and the minimum of it is too small for the network to learn, the following equation has to be used for the normalization:

$$
\dot{\varepsilon}^{*}=\frac{\ln \dot{\varepsilon}-0.95 \ln \dot{\varepsilon}_{\min }}{1.05 \ln \dot{\varepsilon}_{\max }-0.95 \ln \dot{\varepsilon}_{\min }}
$$

where $\dot{\varepsilon}, \dot{\varepsilon}_{\min }, \dot{\varepsilon}_{\max }$ and $\dot{\varepsilon}^{*}$ are the original, minimum, maximum and normalized strain rate, respectively. After pre-proceeding all the inputs, the architecture of the network needs to be elaborated. In order to develop a BP neural network model with desired generalization, 144 random data sets from true stress-true strain curves were adopted to train the model and the remaining 48 data sets were employed as the testing data sets.

The neutron number of the hidden layer is a crucial factor for the efficiency and accuracy of the BP neural network. Traditionally, the trial-and-error method is generally applied to determine the appropriate number of neutrons in the hidden layer. In the present investigation, the performance 
of the network with 8-25 hidden neurons were compared. The performance of different numbers of neurons was evaluated by MSE, as shown in Figure 7. It is revealed that 20 hidden-layer neurons presented the best performance and the MSE is only 0.113 . Therefore, the number of hidden-layer neurons is determined to be 20 .

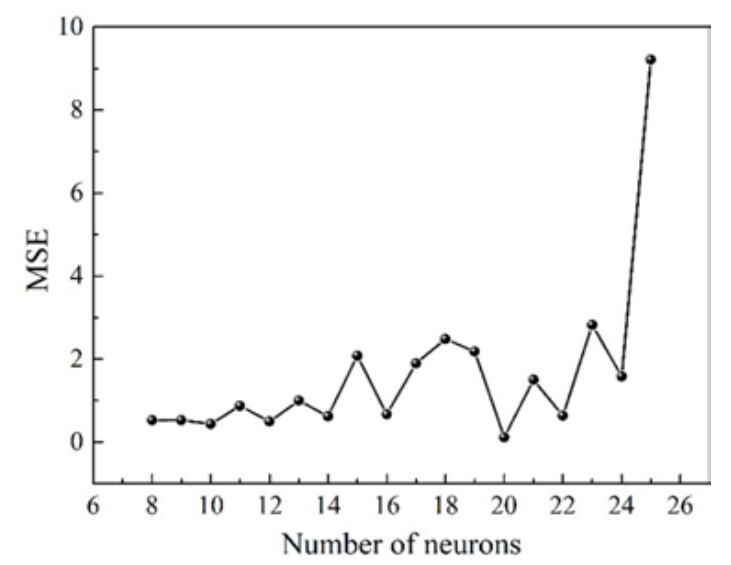

Figure 7. Performance of different numbers of neurons. MSE in the figure represents mean square error.

The accuracy of the established ANN model is further verified by a wide variety of standard statistical performance evaluation methods. The generalization property of the training and testing neural network is quantitatively verified in terms of correlation coefficient $(R)$, relative error $(\delta)$, average absolute relative error $\left(e_{A A R E}\right)$, average root mean square error $\left(e_{R M S E}\right)$, and scatter index $\left(I_{S}\right)$. The above indexes are defined as listed, respectively.

$$
\begin{gathered}
R=\frac{\sum_{i=1}^{N}\left(E_{i}-\bar{E}\right)\left(P_{i}-\bar{P}\right)}{\left(\sum_{i=1}^{N}\left(E_{i}-\bar{E}\right)^{2} \sum_{i=1}^{N}\left(P-\bar{P}_{i}\right)^{2}\right)^{\frac{1}{2}}} \\
\delta=\frac{E_{i}-P_{i}}{E_{i}} \\
e_{A A R E}=\frac{1}{N} \sum_{i=1}^{N}\left|\frac{E_{i}-P_{i}}{E_{i}}\right| \times 100 \% \\
e_{R M S E}=\left[\frac{1}{N} \sum_{i=1}^{N}\left(E_{i}-P_{i}\right)^{2}\right]^{\frac{1}{2}} \\
I_{S}=\frac{e_{R M S E}}{\bar{E}}
\end{gathered}
$$

where $E_{i}$ is the experimental value and $P_{i}$ is the predicted value from the ANN model. $\bar{E}$ and $\bar{P}$ are the mean values of $E_{i}$ and $P_{i}$, respectively. $N$ is the total number of data employed in the research.

The plots of experimental values versus predicted values obtained by the developed ANN model are shown in Figure 8 for both training and testing data sets. The correlation coefficient $(R)$ is a powerful statistical tool to present the strength of the linear relationship between experimental and predicted values. It can be seen from this figure that the $R$ values of training and testing are 0.999 and 0.952 , respectively, which indicates satisfactory adaptation of the established ANN model. In addition, it is noted from Figure 9 that the average absolute relative error $(A A R E)$ and scatter index $\left(I_{S}\right)$ of both training and testing network is small. Most of the relative errors for testing data sets are located in a quite narrow range from $-10 \%$ to $10 \%$. Therefore, it is illustrated that the artificial neural 
network model has been successfully developed to predict the flow behavior of the studied 6A02 aluminum alloy.
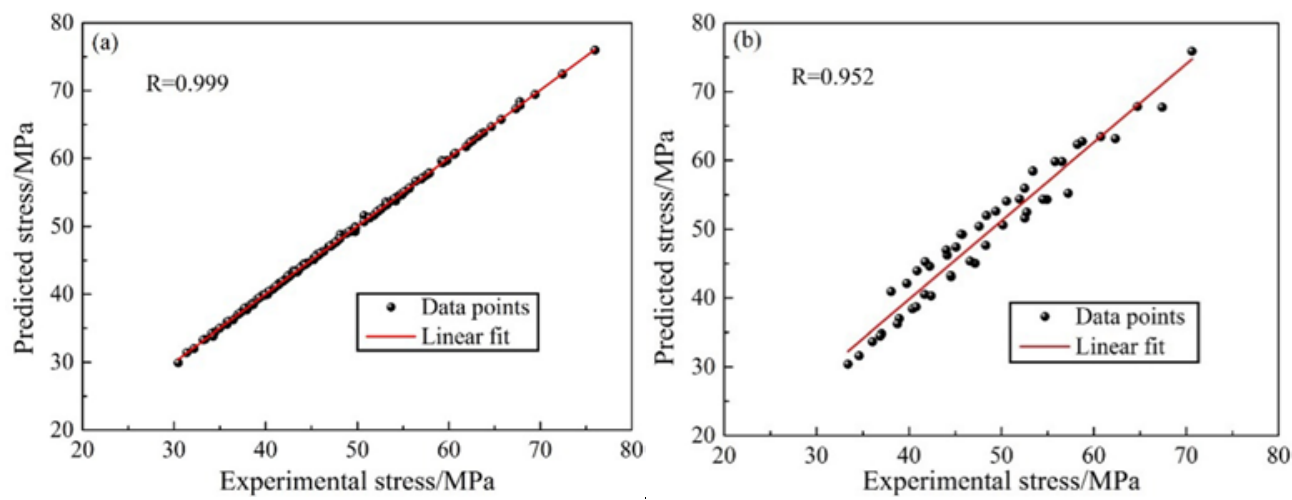

Figure 8. Comparison of flow stress values predicted by artificial neural network (ANN) model and experimental values for (a) training and (b) testing.
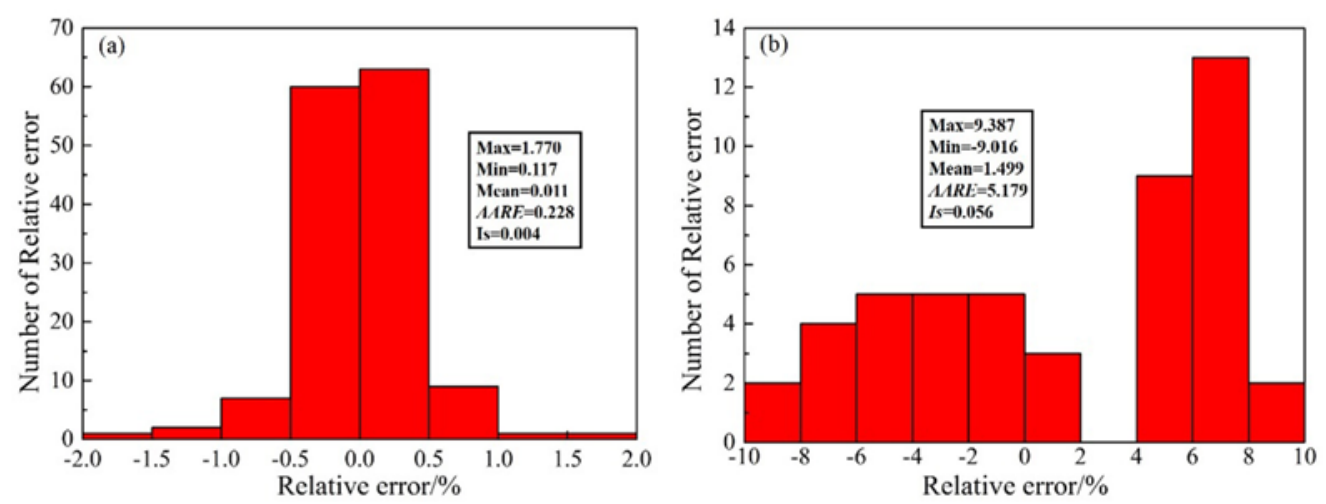

Figure 9. Distribution of relative errors between the developed ANN model and experimental results: (a) training sets and (b) testing sets.

\subsection{Evaluation of Arrhenius-Type Constitutive Model and BP Neural Network}

The relationship between experimental and predicted peak stress by the Arrhenius-type constitutive model is presented in Figure 10. It is noted that most of the data points settled randomly beside the fitting line and the error between experimental and predicted results is obvious. The reason for this consequence lies in accumulated error of all material constants such as $n, Q$ and $\alpha$, et al. Although the linear relationship is not so strong, the relative error can be quite small. The absolute relative errors $(A R E)$ of peak stress at various deformation temperatures and strain rates are revealed in Figure 11. It can be observed that all of the $A R E$ values are below $0.25 \%$ and they drop down as the strain rate increases. Generally, the Arrhenius-type constitutive model is capable of predicting flow stress with high accuracy. However, without the combination of strain in the equation, it can only predict peak stress or flow stress at a certain strain.

The relationship between predicted true stress by the developed ANN model and experimental results at $743 \mathrm{~K} / 0.1 \mathrm{~s}^{-1}$ is illustrated in Figure 12. The predicted true stress is much closer to that of the experiment and the relative error is within the range of $-0.004 \%$ to $0.016 \%$, which indicates that the ANN model has satisfied prediction ability. Moreover, it is noticed that the value of relative error increases with increasing strain. Compared with the Arrhenius-type constitutive model, BP neural network is available to predict true stress in the entire strain range respectively. Additionally, the most significant advantage of BP neural network is to provide a full insight of the relationship between true stress and hot processing parameters such as strain rate, deformation temperature and strain. 
In another words, despite the lack of physical theory support, BP neural network model possesses excellent predicted performance in terms of numerical simulation.

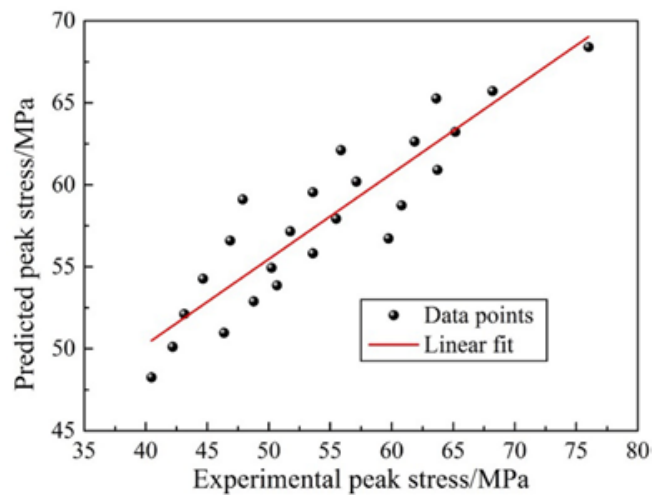

Figure 10. Relationship between predicted peak stress by Arrhenius-type constitutive model and experimental peak stress.

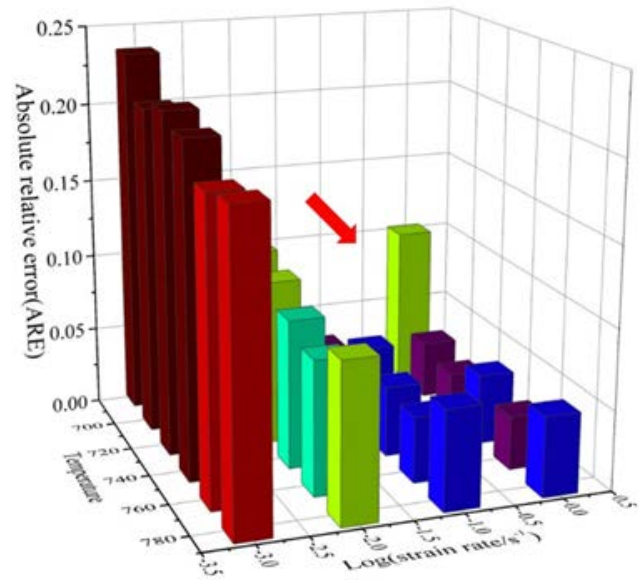

Figure 11. Distribution of absolute relative error (ARE) by Arrhenius-type constitutive model.
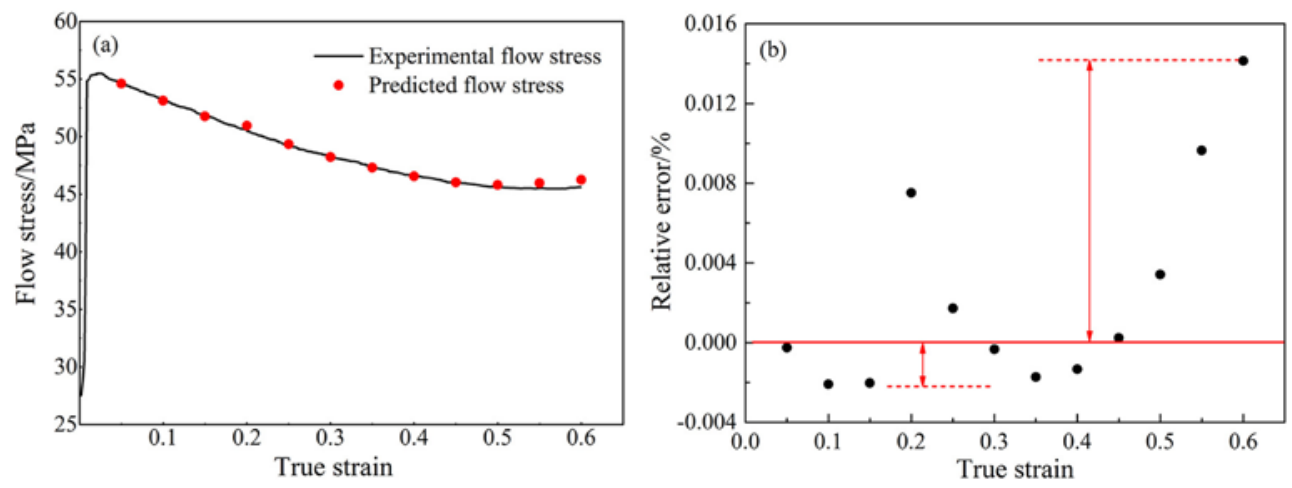

Figure 12. Relationship between predicted flow stress by the developed back-propagation (BP) neural network and experimental results at $743 \mathrm{~K} / 0.1 \mathrm{~s}^{-1}$.

\section{Conclusions}

The hot deformation behavior of 6A02 aluminum alloy was investigated by isothermal compression tests in the temperature range of $683-783 \mathrm{~K}$ at intervals of $20 \mathrm{~K}$ and strain-rate range of $0.001-1 \mathrm{~s}^{-1}$. The Arrhenius-type constitutive model and BP neural network were established to 
characterize the flow behavior of the experimental alloy, respectively. Furthermore, the generalization performance of both developed models were evaluated. The essential differences between the two methods were subsequently revealed.

(1) There is a nonlinear relationship between hot processing parameters and flow stress in the isothermal deformation of 6A02 aluminum alloy. The true stress decreases with increasing temperatures and decreasing strain rates. Besides, typical work hardening and dynamic softening features can be observed from the true stress-true strain curves of 6A02 aluminum alloy.

(2) The Arrhenius-type constitutive model is established to present the deformation behavior of the studied alloy. The activation energy $(Q)$ is calculated to be $168.916 \mathrm{~kJ} \mathrm{~mol}^{-1}$, which is much smaller than other kinds of aluminum alloy. Moreover, the absolute relative error by this model is no more than $0.25 \%$, which demonstrates high accuracy of the established model.

(3) A back-propagation neural network with one hidden layer and 20 neurons in the hidden layer was developed to characterize the flow behavior of the alloy. The relative errors were limited in the range of $-0.004 \%$ to $0.016 \%$, which suggested an excellent predicted performance of the ANN model. Moreover, the back-propagation neural network can be used to predict the true stresses in the whole strain range conveniently.

Acknowledgments: This work was sponsored by the National Natural Science Foundation of China (No. 51371038 and 51604034), the China Postdoctoral Science Foundation (No. 2014M551234), the Specialized Research Fund for the Doctoral Program of Higher Education (No. 20132302120002), the Fundamental Research Funds for the Central Universities (No. HIT. NSRIF. 2014006) and Heilongjiang Postdoctoral Fund (No. LBH-Z14096).

Author Contributions: Ying Han conceived and designed the experiments; Shun Yan performed the experiments; Ying Han and Yu Sun analyzed the data; Hua Chen contributed analysis tools; Ying Han and Yu Sun wrote the paper.

Conflicts of Interest: The authors declare no conflict of interest. The founding sponsors had no role in the design of the study; in the collection, analyses, or interpretation of data; in the writing of the manuscript, and in the decision to publish the results.

\section{References}

1. Deng, Y.; Yin, Z.M.; Huang, J.W. Hot deformation behavior and microstructural evolution of homogenized 7050 aluminum alloy during compression at elevated temperature. Mater. Sci. Eng. A 2011, 528, 1780-1786. [CrossRef]

2. Zhang, H.; Li, L.X.; Yuan, D.; Peng, D.S. Hot deformation behavior of the new Al-Mg-Si-Cu aluminum alloy during compression at elevated temperatures. Mater. Charact. 2007, 58, 168-173. [CrossRef]

3. Quan, G.Z.; Mao, Y.P.; Li, G.S.; Lv, W.Q.; Wang, Y.; Zhou, J. A characterization for the dynamic recrystallization kinetics of as-extruded 7075 aluminum alloy based on true stress-strain curves. Comp. Mater. Sci. 2012, 55, 65-72. [CrossRef]

4. Shakiba, M.; Parson, N.; Chen, X.-G. Modeling the effects of $\mathrm{Cu}$ content and deformation variables on high-temperature flow behavior of dilute Al-Fe-Si using an artificial neural network. Materials 2016, 9, 536. [CrossRef]

5. Sun, Y.; Hu, L.; Ren, J. Modeling the constitutive relationship of powder metallurgy Ti-47Al-2Nb-2Cr alloy 400 during hot deformation. JMEPG 2015, 24, 1313-1321. [CrossRef]

6. EI Mehtedi, M.; Gabrielli, F.; Spigarelli, S. Hot workability in process modeling of a bearing steel by using combined constitutive equations and dynamic material model. Mater. Des. 2014, 53, 398-404. [CrossRef]

7. Lin, Y.C.; Li, K.K.; Li, H.B.; Chen, J.; Chen, X.M.; Wen, D.X. New constitutive model for high-temperature deformation behavior of inconel 718 superalloy. Mater. Des. 2015, 74, 108-118. [CrossRef]

8. Ji, G.L.; Li, Q.; Ding, K.Y.; Yang, L.; Li, L. A physically-based constitutive model for high temperature deformation of Cu-0.36Cr-0.03Zr alloy. J. Alloy. Compd. 2015, 648, 397-407. [CrossRef]

9. Sarebanzadeh, M.; Mahmudi, R.; Roumina, R. Constitutive analysis and processing map of an extruded Mg-3Gd-1Zn alloy under hot shear deformation. Mater. Sci. Eng. A 2015, 637, 155-161. [CrossRef]

10. Xu, Y.; Hu, L.X.; Deng, T.Q.; Ye, L. Hot deformation behavior and processing map of as-cast AZ61 magnesium alloy. Mater. Sci. Eng. A 2013, 559, 528-533. [CrossRef] 
11. Deng, T.Q.; Ye, L.; Sun, H.F.; Hu, L.X.; Yuan, S.J. Development of flow stress model for hot deformation of Ti-47\%Al alloy. Trans. Nonferr. Met. Soc. China 2012, 21, 308-314. [CrossRef]

12. Khamei, A.A.; Dehghani, K. Effects of strain rate and temperature on hot tensile deformation of severe plastic deformed 6061 aluminum alloy. Mater. Sci. Eng. A 2015, 627, 1-9. [CrossRef]

13. Han, Y.; Qiao, G.J.; Sun, J.P.; Zou, D.N. A comparative study on constitutive relationship of as-cast $904 \mathrm{~L}$ austenitic stainless steel during hot deformation based on Arrhenius-type and artificial neural network models. Comput. Mater. Sci. 2013, 67, 93-103. [CrossRef]

14. Li, B.; Pan, Q.L.; Yin, Z.M. Microstructural evolution and constitutive relationship of Al-Zn-Mg alloy containing small amount of Sc and Zr during hot deformation based on Arrhenius-type and artificial neural network models. J. Alloy. Compd. 2014, 584, 406-416. [CrossRef]

15. Ji, G.L.; Li, F.G.; Li, Q.H.; Li, H.Q.; Li, Z. Prediction of the hot deformation behavior for Aermet100 steel using an artificial neural network. Comput. Mater. Sci. 2010, 48, 626-632. [CrossRef]

16. Li, H.Y.; Wang, X.F.; Wei, D.D.; Hu, J.D.; Li, Y.H. A comparative study on modified Zerilli-Armstrong, Arrhenius-type and artificial neural network models to predict high-temperature deformation behavior in T24 steel. Mater. Sci. Eng. A 2012, 536, 216-222. [CrossRef]

17. Quan, G.Z.; Lv, W.Q.; Mao, Y.P.; Zhang, Y.W.; Zhou, J. Prediction of flow stress in a wide temperature range involving phase transformation for as-cast Ti-6Al-2Zr-1Mo-1V alloy by artificial neural network. Mater. Des. 2013, 50, 51-61. [CrossRef]

18. Haghdadi, N.; Zarei-Hanzaki, A.; Khalesian, A.R.; Abedi, H.R. Artificial neural network modeling to predict the hot deformation behavior of an A356 aluminum alloy. Mater. Des. 2013, 49, 386-391. [CrossRef]

19. Wu, H.; Wen, S.P.; Huang, H.; Wu, X.L.; Gao, K.Y.; Wang, W.; Nie, Z.R. Hot deformation behavior and constitutive equation of a new type Al-Zn-Mg-Er-Zr alloy during isothermal compression. Mater. Sci. Eng. A 2016, 651, 415-424. [CrossRef]

20. Zhou, P.; Ma, Q.X.; Luo, J.B. Hot deformation behavior of as-cast 30Cr2Ni4MoV steel using processing maps. Metals 2017, 7. [CrossRef]

21. Xiang, S.; Liu, D.Y.; Zhu, R.H.; Li, J.F.; Chen, Y.L.; Zhang, X.H. Hot deformation behavior and microstructure evolution of 1460 Al-Li alloy. Trans. Nonferrous Met. Soc. China 2015, 25, 3855-3864. [CrossRef]

22. Rezaei Ashtiani, H.R.; Parsa, M.H.; Bisadi, H. Constitutive equations for elevated temperature flow behavior of commercial purity aluminum. Mater. Sci. Eng. A 2012, 545, 61-67. [CrossRef]

23. Yang, Q.; Yang, D.; Zhang, Z.; Cao, L.; Wu, X.; Huang, G.; Liu, Q. Flow behavior and microstructure evolution of 6A82 aluminium alloy with high copper content during hot compression deformation at elevated temperatures. Trans. Nonferrous Met. Soc. China 2016, 26, 649-657. [CrossRef]

24. Chen, L.; Zhao, G.; Yu, J. Hot deformation behavior and constitutive modeling of homogenized 6026 aluminum alloy. Mater. Des. 2015, 74, 25-35. [CrossRef]

25. Chen, L.; Zhao, G.; Yu, J.; Zhang, W. Constitutive analysis of homogenized 7005 aluminum alloy at evaluated temperature for extrusion process. Mater. Des. 2015, 66, 129-136. [CrossRef]

26. Liu, W.; Zhao, H.; Li, D.; Zhang, Z.; Huang, G.; Liu, Q. Hot deformation behavior of AA7085 aluminum alloy during isothermal compression at elevated temperature. Mater. Sci. Eng. A 2014, 596, 176-182. [CrossRef]

27. Hollomon, J.H.; Zener, C. Problems in fracture of metals. J. Appl. Phys. 1946, 82, 82-90. [CrossRef]

28. Zhao, J.W.; Ding, H.; Zhao, W.J.; Huang, M.L.; Wei, D.B.; Jiang, Z.Y. Modelling of the hot deformation behaviour of a titanium alloy using constitutive equations and artificial neural network. Comput. Mater. Sci. 2014, 92, 47-56. [CrossRef]

(C) 2017 by the authors. Licensee MDPI, Basel, Switzerland. This article is an open access article distributed under the terms and conditions of the Creative Commons Attribution (CC BY) license (http:/ / creativecommons.org/licenses/by/4.0/). 